For citation: Rudenko, M. N. \& Hochradel, R. (2017). Assessing the Impact of the Competency Level on the Success of Companies' Integration. Ekonomika regiona [Economy of Region], 13(1), pp. 106-113

doi $10.17059 / 2017-1-10$

UDC: 33.65 .005 .5

M. N. Rudenko ${ }^{\text {a) }}$ R. Hochradel ${ }^{6)}$

a) Perm State National Research University (Perm, Russian Federation; e-mail: m.ru.ko@mail.ru)

${ }^{6)}$ Delta State University (Cleveland, USA)

\title{
ASSESSING THE IMPACT OF THE COMPETENCY LEVEL ON THE SUCCESS OF COMPANIES' INTEGRATION ${ }^{1}$
}

The integration of companies is crucially important in the ongoing globalization processes. Companies must unify the material assets and optimize property. The integration of the company, incrementally, and competency development is also essential in order to expand the competitiveness of the company's integrated structure. Identification and management of competencies are especially important for the enterprise structures, which carry out the integration processes. The level of competepcy development and the types of competencies may or may not be similar. The aim of this research is to-suecis, and develop an organizational competency structure, which groups individual competencies of an Granlzation into various segments based on their similarity. This research is relevant due to the need to. vst matize a to streamline competencies in order to better identify them and develop a set of measure for thir mont in the theoretical literature analysis allowed us to create a model that characterizes the dsumed-imp ctof the competencies on the successful integration of companies. Based on the data, wd avided the rar zational competencies into five major categories are. An empirical assessment of the in act of the com petencies on the market success of the integration of enterprise structures is provided This research indicales that the success of such integration is substantially determined by the formation an development the competencies. The authors interviewed top managers of 225 medium and large-sted ompanies from all over the country were (the questionnaire was created by Rudenko M.N.) The time lag is 5 y ans. Thereby, the results can be used in the process of regional policy formation.

Keywords: competency, entrepreneurship negration, identifcation, correlation, regression, the market value of assets, customer satisfaction, relationship, Ma A succes

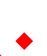

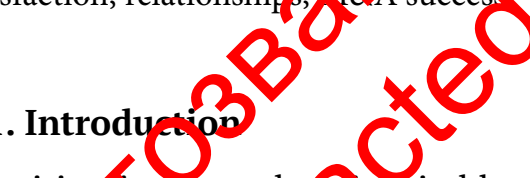

tion of government and business that is realized in the form of public-private partnership $[8,9]$.

Researchers are finding that M\&A do not nec-

Growing competition in all marke s/gevitably brings companies to de ermine thếneed of consolidating strategiesured in mosus and acquisitions (M\&A) which ena's (oplpanies to survive. Most recent studies $n$ M \& transactions explore the economic reasons for mergers and acquisitions $[1,2]$, the motivation of the contracting parties [3, 4], and the optimization of production and property or decrease in competition [5], and the impact of culture on M\&A success $[6,7,8]$ to name a few. Forms of M\&A have been researched as well. Shemetov notes the following basic forms of integration are offered: integration of assets in mergers and acquisitions; integration of information resources and technologies in the establishment of joint ventures and projects; horizontal integration shipbuilders in large corporations; integration of suppliers, shipbuilders and customers, that is vertical integration in different kinds of its realization (direct, reverse or total); and integra-

${ }^{1}$ @ ) Rudenko M. N., Hochradel R. Text. 2017. essary lead to financial success $[7,10]$. The analysis of the theory and practice of M\&A transactions shows that their success and the competitiveness of the integrated structure is becoming increasingly important, not only due to the unification of tangible assets of the companies and the optimization of the property complex, but also because the increase and development of integrated company competencies are vital.

Current research regarding the competency-based approach insufficiently identifies and specifies competencies of the companies involved. In many cases, competencies imply a rather abstract phenomenon. These competencies, including organizational capabilities, entrepreneurial competency, competitive scope, result in firm performance [3]. However, the issues of the organizational competencies are considered only descriptively. They state a special and significant role of these competencies and give some general characteristics and imply the link with competitive- 
ness. Most research refers to the grouping of individual competencies in the organization based on segments in their industry [11]. This issue is relevant because of the need to systematize and streamline competencies in order to better identify them, classify them, and develop a set of measures for their control. Crevens suggests classifying competencies based on the functional processes in which he divides into external, internal and bilateral processes [11]. According to Crevens, the external group includes the processes that are directed from the external environment into the internal ones. Companies assume that knowledge of external processes impacts the internal condition of the company and the interaction of external companies.

During the M\&A process, firms focus on the internal processes. Thus, this research investigates the internal processes, such as the division into segments, the relationships with customers, and the formation of the distribution channels, as identified by Crevens, as the processes that occur within the company and determines customer satisfaction. Crevens considers that these internal processes are due to the functional aspects of the company's activities, such as financial man agement, production, and development of personnel [11]. Bilateral processes are defined by bath external and internal processes. They are 1 sociated with sub-processes such as procun ment, development strategies, pricing, and ser tree. This r search considers the bilateral processes (conte tencies) as diversified and mulifievel (strat vic sospects of the company are on idered in the same order, with its operatin (lements). Hover, it is beyond the scope of this research of fury consider the proposed classisadion resoraing the complete impact of these competis is on the organization during the M\&A press.

\section{Competencies}

Regardless of the reasons for the M\&A, identification and management of competencies are especially important for business organizations which carry out the integration processes. Tanure, Cancado, Durate, \& de Muylder indicate that firms need to evaluate these competencies during the M\&A negotiations, but pressure to close the deal quickly may overlook organizational fit and rely solely on strategic fit [12]. Datta found that management style impacted the success of M\&A more than operational integration [13]. Haspeslagh and Jemison noted that the need for strategic interdependence and the need for organizational autonomy were two key dimensions underlying the integration process [14]. Thus, the competencies of each company involved in the M\&A process must be evaluated. One company might have more development competencies, another company might have fundamentally different competencies, or two companies might have similar competencies (meaning similar competencies of the same level of development). In this context, for the management of the combined structure, it is necessary to determine issues, such as,

1) the competencies that need to be changed;

2) the competencies that need to be developed;

3) the competencies that need to be eliminated;

4) how to evaluate the success of the integration of the various competencies of business structures. These processes create value for the new organization dyato the learning process that is required $[15,16,1]$.

\section{Vethodology}

This re earcriconsigad of wo studies: a qualitative study and a gunt tative study. The qualitative st dy consist d of an intensive interview of 15 in arket expers o, aetermine their view of the ompetencies need for a successful M\&A process. The struture of the competencies of the company was determined by the result of the informaton obtained in the qualitative research and becme the foundation of the development of the quantitative research. This qualitative research identified the variables that characterize the success of the integration of enterprise structures. These seven variables include: 1 ) the market value of assets, 2) the share of intangible assets in the company's value, 3) customer satisfaction, 4) employee satisfaction, 5) operational efficiency, 6) revenue growth, and 6) EBITDA margin.

From the information obtained in the qualitative research, a questionnaire was developed. In analyzing the situational successful integration of enterprise structures, this research assumes there is no general optimal alternative enterprise behavior, but takes into consideration a number of situational alternative actions. These alternative actions are essentially contextual external and internal factors, including:

- price trends in the industry which describe the price competition between the manufacturers/ brokers;

- competitive dynamics characterized by the intensity of competition in the industry;

- the development of technology such as the speed and direction of technological evolution in the industry;

- changes in consumer behavior such as change preferences, expectations, representa- 


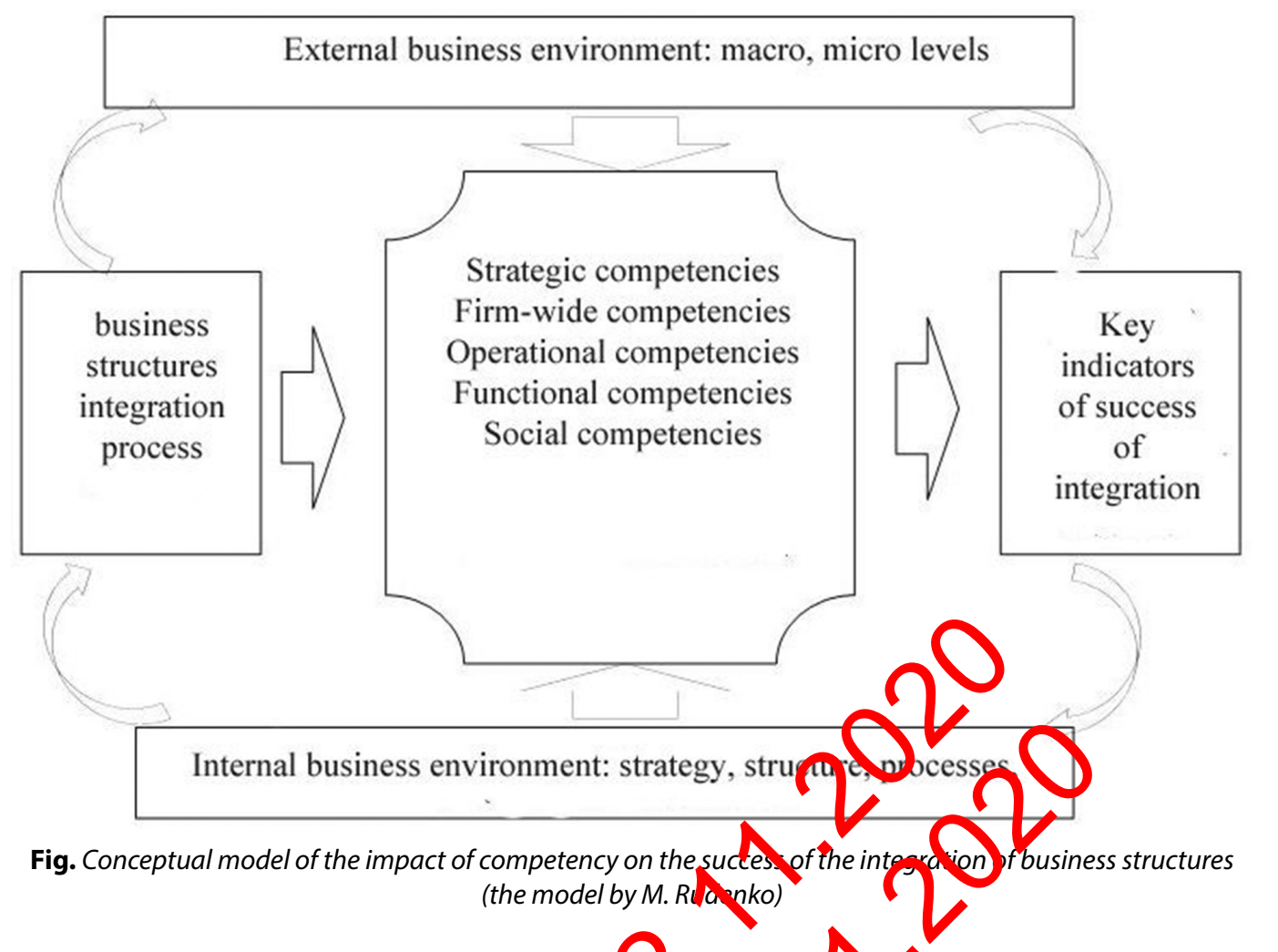

tions, and change cultural values and stereotypes to exist independently, unlike reflective models. over time;

- the growth of the market, indicated by the dynamic change in the rate of market development.

For the operationalization of the ilu tuted construct, it is necessary to choose neasuring model, which identify the indicatos measur a on the basis of theoretical cons agion. In ran cases, models are operational 20 by severa 1 , cators identified as one co mp nent. It s usully not enough to clearly express all the r. 19, ionships, which suggests the use of aggrege te Mdicators. Given the direction and the relationship between the apparent and hidden ynges, we distinguish two measurement models 1,1$]$ :

1. Reflective measurement model: the indicators form a single, observable manifestation of constructs that correctly reflect the competencies and are correlated. Changing the structure entails changing the observed indicators without changing the content of the construct. Therefore, only measurement process can be changed. Measuring the theoretical construct by reflective variables does not accurately reflect real situations regarding the construct. Thus, the use of reflective measurement models increases the probability of error.

2. Formative measurement model: the construct is formed based on the indicators. Specific indicators indicate substantial characteristics of the construct. Changes, such as removing one of the indicators, lead to the involuntary changing the construct. Formative factors are designed Toblems otcur when there is a strong correlation since tho formative model is based on the principles of multiple regression analysis.

For this research, it is necessary to utilize the constructs of both the reflective measurement model and the formative model. The use of the formative model is necessary due to the need to mark the success of the integration since, in the context of the M\&A situations, the successes of integration requires the evaluation of many different indicators. Based on the assumptions and analysis of theoretical sources a model was developed characterizing the estimated impact of competencies on the successful integration companies (see Fig.). This research tests this model based on the empirically proposed logical relationships. The analysis of the data makes possible to draw a conclusion about the presence/absence of a direct/ indirect correlation between organizational competencies and the successful integration of enterprise structures.

In structuring the model for each indicator, a questionnaire was developed utilizing questions that meet the relevant situational competency approach. This situational competency approach was measured using five indicators:

1) the dynamic of prices,

2) the dynamic of competition,

3) technological developments,

4) changes in consumer behavior, 
5) market growth.

Market growth was measured using two variables:

1) the growth of the market over the past five years,

2) the projected growth of the market over the next five years.

The questionnaire was scored using a grading scale comprised of several variants of the respondent's answers, resulting in a total value from 1 to 5 . The advantages of this grading scale are a simplification for respondents to respond to the questions, reduction the time needed to complete the questionnaire, and a reduction of the number of errors when completing the questionnaire.

The empirical quantitative survey was conducting using an online platform for the distribution of the questionnaire. A total of 223 businesses were surveyed resulting in 214 (96\%) usable responses. The survey participants were key personnel in various companies, including board members, senior managers, division heads and department heads in mid- and lower-level management. The respondents expressed interest in the involvement of the process of M\&A. Specifically, these respondents expressed in terest in the generalization of the results of the company/brand activity ( $87.6 \%$ of the reopondents), indicating a high degree of involven ent in the research process. $61 \%$ of respond its noted that brands are responsible for the $B, C$ marke $C$, $13.6 \%$ work with brands in intos rial markes, and $25.5 \%$ are employed and $\mathrm{wo}$ k with brang B2B markets. However, it m ast be noted that some of the respondents failea to provide or plete information, such as esponding "Id o 't Know" and leaving some answe olank. And hese responses were not the nor $1, t$, eil presence may reduce the representative $s \mathrm{~s}$ of the sample, and thus, the generalizability of the research. The data was analyzed using the software package IBM SPSS.

\section{Hypotheses}

The purpose of this research is to determine the degree to which the success of the process of the integration of the enterprise structures is determined by the successful integration of the identified competencies. Specifically, this research posits the following hypotheses:

H1: higher levels of development of functional competencies result in greater success in the processes of integration of the companies;

H2: better identified and developed strategic competencies of the companies result in more efficient processes of integration;
H3: more company-wide developed competencies result in greater probability of success of the integration of enterprise structures;

$\mathrm{H} 4$ : higher levels of the development and identification of the operational competencies result in a more successful process of the company's integration;

H5: higher levels of the development and identification of the social competencies result in a more successful process of the company's integration;

H6: the market contextual factors have little direct impact on the success of the integration of companies.

\section{Analysis}

The analysis of the lata consisted of dividing the organizational tructures into five main competencies. The syakegic orpetencies are those competen(ie winch a te nal characteristics of the organi sution and $n$ ay predetermine the future devolopment o thy company. The characteristi are creativity, innovation, cognition, communication, enter ise, intellect, and entrepre1 eurial drive. These competencies are needed when deternining the developmental potential, the ration of customer value and market evolution, and the global development of the organizatin. Additionally, this study found that strategic competencies are revealed the characteristics of the entrepreneur as a person, which impact the organization due to the level of capability of the individual company's executives and their aggregate managers and employees.

Functional competency categories are defined as those aspects of the company which determine the internal processes of the business structure [11]. These characteristics are production, marketing, human resources (HR) research and development $(R \& D)$, and so forth. It is worth noting that this category has been assigned to the mechanism of cross-functional cooperation, which allows the customer to expand the field to improve the satisfaction of internal and external customers.

The next competency is identified as organizational competency which consists of the operational components, including the market vision, the identification of value for the customer and stakeholders, the ability to form a customer-oriented business model (a combination of resources), the ability to create organizational routines, the ability to bring the case to its logical conclusion, the operational management of enterprise structure, the rate of reaction to emerging changes and the speed of adoption of organiza- 
tional decisions (goal-setting, asset management focus, creativity), the effective internal information system-detailing communicative competency, and entrepreneurship. These components allow the organization to implement the strategy and is adopted in the framework of the existing business model of an integrated company.

The firm-wide competencies consisted of those characteristics that identified the value of the activities of the business structure. These characteristics were grouped together and included the competencies of organizational culture, understanding of the place of information systems in the company's architecture, the stress of the company, the company's infrastructure, and the technical and technological aspects of activity.

The final competency is the social basis of organizational competencies. Some of the characteristics of this competency include leadership, cooperation between employees, the ability to resolve conflict, teambuilding, and the ability to manage talent. These characteristics play an important role in the integration of the social aspects of an organization.

\section{Results}

The reliability and validity of the factors forming the structure of the measurement modo were evaluated to determine the empirical asse snent of the impact of the competencies on 1 e market success of the integration of enternriestructures. Reliability, or the accuracy of theneasurente is a normal degree of accurac $y$ a freedo random errors of measuren en represented by the model. Cronbach's alnha is used to dof mine the internal consistency or reliability of a construct $[18,19,20,10]$. It evolates th $q$ avrage correlation items that are believe a no asure the same construct. A high level of robmity is indicative of the amount of system dispersion. If the indicators can explain part most of the variance, the measurement structure is considered robust. To assess the reliability of the model, a Cronbach's alpha was determined for each construct in the proposed model. The Cronbach's alpha for each competency is detailed in Table 1 .

Validity, or the conceptual accuracy of the measurement model, describes the degree to which the measurement indicator is the measuring what should be measured and is free from system error. The Kaiser-Meyer-Olkin (KMO) index was used to determine the validity of each competency. The KMO index of 0.5 or greater is considered valid [21]. Detailed results of the evaluation of the validity of the measurement models competencies are found in Table 1.

Table 1

Analysis of Competency Reliability and Validity (designed by M. N. Rudenko)

\begin{tabular}{|l|c|c|c|}
\hline \multicolumn{1}{|c|}{ Competency } & Cronbach's $\boldsymbol{\alpha}$ & KMO & Variance, $\%$ \\
\hline Functional & $0.810^{*}$ & $0.756^{* *}$ & 30.81 \\
\hline Strategic & $0.810^{*}$ & $0.784^{* *}$ & 30.81 \\
\hline Social & $0.785^{*}$ & $0.702^{* *}$ & 27.66 \\
\hline Firm-wide & $0.879^{*}$ & $0.865^{* *}$ & 33.50 \\
\hline Operational & $0.789^{*}$ & $0.774^{* *}$ & 20.92 \\
\hline Dynamic Market & $0.841^{*}$ & $0.784^{* *}$ & 38.01 \\
\hline
\end{tabular}

* Cronbach's alpha $>0.60 ;{ }^{* *} \mathrm{KMO}>0.50$.

The construction of functional competencies demonstrates satisfactory reliability and adequate validity (see Table 1). All correctional indicators are greater than the minimum accepted level of 0.4 , indicatir o a elatively high linear relationship between th e yariables (see Table 2). Thus, the functiona competen determined by industrial com encies, ind ating the construct is measuring what is intend ed to be measured. This is duerto the results of he value of 0.714 and the KM, test result of 756 .

Construction of strategic competencies Tabole 1) also demonstrates good reliability and lidity. Crunbach's coefficient $(0.81)$ is considered 8 od, The correction value of all factors, in additic $y$ to the entrepreneurial drive, is above the 0.4 vark (see Table 2). It should be noted that the factor responsible for cognition demonstrates the highest value of correction at 0.679 . The assessment of convergence and discriminant validity by factor analysis also seems positive, since all values are greater than 0.4 . The cognitive factor, which has the highest (0.784) value KMO criterion, is a good estimate.

The construction of social competency (Table 1$)$ shows satisfactory reliability $(0.785)$ and validity (0.703), indicating a good linear relationship for the competency model. However, the values of 0.347 for the competency of the socialization of the individual is the lowest value in the organization construct (see Table 2). This low value indicates the respondents do not pay enough attention to the socialization of employees during M\&A and, thus, do not consider the competency significant.

Both the constructs of firm-wide and operational competencies (see Table 1) are found to have high reliability and validity. The components of the competency model result in correlation values greater than 0.4 , indicating a high linear dependence (see Table 2). The model results, with a value of 0.767 , indicates that the construct of the ability to creatively transform resources has the strongest influence on firm-wide competencies. 
Table 2

Analysis of the Competencies Measurement Models (designed by M. N. Rudenko)

\begin{tabular}{|c|c|c|}
\hline Competency/Component & $\begin{array}{l}\text { Adjustments } \\
\text { to common } \\
\text { correlation }\end{array}$ & $\begin{array}{l}\text { Factor } \\
\text { weight }\end{array}$ \\
\hline \multicolumn{3}{|c|}{ Functional } \\
\hline Fiscal jurisdiction & 0.454 & 0.380 \\
\hline Manufacturing & 0.616 & $0.714^{*}$ \\
\hline Logistics & 0.443 & $0.519^{*}$ \\
\hline Marketing & 0.418 & $0.456^{*}$ \\
\hline HR & 0.474 & $0.570^{*}$ \\
\hline Value creation & 0.430 & $0.496^{*}$ \\
\hline Cross functional interaction & 0.510 & $0.610^{*}$ \\
\hline \multicolumn{3}{|l|}{ Strategic } \\
\hline Creativity & 0.545 & $0.638^{*}$ \\
\hline Innovation & 0.528 & $0.624^{*}$ \\
\hline Cognition & 0.679 & $0.801^{*}$ \\
\hline Communication & 0.540 & $0.589^{*}$ \\
\hline Enterprise & 0.512 & $0.500^{*}$ \\
\hline Intellect & 0.564 & $0.614^{*}$ \\
\hline Entrepreneurial drive & 0.471 & $0.500^{*}$ \\
\hline \multicolumn{3}{|l|}{ Social } \\
\hline Leadership & 0.452 & $0.492^{*}$ \\
\hline Staff interaction & 0.482 & $0.530^{*}$ \\
\hline Teambuilding & 0.435 & $0.598^{*}$ \\
\hline Amenablerelationship & 0.514 & 0.680 \\
\hline Conflict resolution & 0.471 & $0.562^{*}$ \\
\hline Socialization & 0.347 & $0.417^{*}$ \\
\hline Manage talent & 0.454 & $97^{*}$ \\
\hline \multicolumn{3}{|l|}{ Firm-wide } \\
\hline \multicolumn{3}{|l|}{ Space information systems } \\
\hline \multicolumn{3}{|l|}{ Technical/technological } \\
\hline \multicolumn{3}{|l|}{ Transform resources creatively } \\
\hline \multicolumn{3}{|l|}{ Infrastructure competency } \\
\hline \multicolumn{3}{|l|}{ Collective knowledge } \\
\hline Effective communicat & 0.5 & $0.502^{*}$ \\
\hline Strong corporate cultu & 2.4 & $0.594^{*}$ \\
\hline \multicolumn{3}{|l|}{ Resistance to stress } \\
\hline & & \\
\hline Market vision & 0.458 & $0.527^{*}$ \\
\hline Customer/stakeholder value & 0.522 & $0.623^{*}$ \\
\hline Customer-oriented business & 0.541 & $0.627^{*}$ \\
\hline Organizational routines & 0.585 & $0.764^{*}$ \\
\hline Case Resolution & 0.471 & $0.784^{*}$ \\
\hline Enterprise structure management & 0.507 & $0.635^{*}$ \\
\hline Rate of reaction to needed change & 0.515 & $0.650^{*}$ \\
\hline $\begin{array}{l}\text { Effective internal information } \\
\text { system }\end{array}$ & 0.559 & $0.699^{*}$ \\
\hline Entrepreneurship & 0.523 & $0.695^{*}$ \\
\hline \multicolumn{3}{|c|}{ Dynamic Market } \\
\hline Variability of consumer behavior & 0.685 & $0.788^{*}$ \\
\hline $\begin{array}{l}\text { Variability of competitors' } \\
\text { strategies }\end{array}$ & 0.759 & $0.845^{*}$ \\
\hline Variability of industry technology & 0.711 & $0.801^{*}$ \\
\hline Industry price dynamics & 0.675 & $0.644^{*}$ \\
\hline Market dynamics & 0.547 & $0.541^{*}$ \\
\hline Anticipated market dynamics & 0.335 & 0.316 \\
\hline
\end{tabular}

${ }^{*}$ Factor weight $>0.4$.
The operating model competency includes the construct regarding the firm's ability to bring the case to its logical conclusion. This construct has the greatest impact on the competency with a value of 0.784 (Table 1) with all components indicating a high linear dependence (see Table 2).

The competency of the dynamic market environment indicates a high reliability with a Cronbach's alpha of 0.841 (see Table 1). This competency includes two constructs with a high reliability: the degree of variability of competitors' strategies over the past 5 years and the degree of variability of technology in the industry (see Table 2). This competency also indicates good validity with a KMO of .784. Based on the results of the analysis, variablo-income growth was not included in the comp tency. This result can be interpreted as an ncease in income growth is not an indicator charycerizin profitability.

Upon the completicn of the determination of reliability an ${ }^{-1}$ validity a regression analysis was conduct to evaluate the hypotheses. The premise 1 that the more developed certain expertise is, the greater the success of the integration of enterpirise structures could be in M\&A. The analys evaluated each competency model beginning by assessing for violations of the assumptions. The regression analysis of functional competencies found no violations of assumptions. The eval- uation of criteria describing multicollinearity tolerance and VIF, resulted in acceptable values, indicating low multicollinearity, which, if found, would increase the likelihood of not interpreting of the regression analysis correctly. Standardized residuals are in the range of \pm 3 standard deviation; the maximum deviation of acceptable residuals is 2.25. Subsequently, a Durbin-Watson test, which checks for the presence of autocorrelation, was conducted. The result, a value of 2.32 , is below the permissible values border [22, 23, 24]. The details of these analyses are found in Table 3.

The analysis of the regression coefficients revealed that the variable which characterizes the competency of logistics does not show the effect of particulate ( $t=1.797)$. In general, the functional competency, with a corrected $R^{2}$ value of $15.6 \%$, explains the variance of the market success of the integration of business structures, and, with a very high $F$-test value (4.780), the hypothesized impact of functional competencies for successful integration of enterprise structures during M\&A is confirmed.

After conducting a regression analysis of strategic competencies, no violations of model assumptions were noted. Criteria describing multicollinearity tolerance and VIF are within ac- 
Table 3

Evaluation of the Regression Model Competencies Impact on the Success of the Integration of Business Structures

\begin{tabular}{|l|c|c|c|c|c|c|}
\hline \multirow{2}{*}{ Competency/Component } & \multicolumn{5}{|c|}{ General Model } \\
\cline { 2 - 7 } & $\boldsymbol{R}^{\mathbf{2}}$ & Adjusted $\boldsymbol{R}^{\mathbf{2}}$ & Standardized error & $\boldsymbol{F}$ & sig & Durbin-Watson \\
\hline Functional & 0.197 & 0.156 & 2.581 & 4.780 & $\ldots$ & 2.322 \\
\hline Strategic & 0.255 & 0.210 & 2.497 & 5.677 & $\ldots$ & 2.080 \\
\hline Social & 0.211 & 0.171 & 2.588 & 5.225 & $\ldots$. & 2.208 \\
\hline Firm-wide & 0.305 & 0.193 & 2.523 & 2.736 & $\ldots$ & 2.095 \\
\hline Operational & 0.341 & 0.289 & 2.369 & 6.554 & $\ldots$. & 2.116 \\
\hline Dynamic Market & 0.142 & 0.098 & 2.668 & 3.223 & $\ldots$ & 2.242 \\
\hline Model & 0.450 & 0.407 & 2.163 & 10.378 & $\ldots$. & 1.966 \\
\hline
\end{tabular}

ceptable values. The impact of strategic competencies on the successful integration of business organizations is $21.0 \%$ with one of the highest $F$-test values (5.677). When evaluating the individual constructs, the analysis revealed that cognition has a negative impact on the competency. In a further evaluation, it was found on the one hand, successful companies very positively evaluated the impact of this variable on the successful of the integration of the companies. However, on the other hand, it can be assumed that the effects of this indicator as a determination of integration success can have a negative impact. The research data gathered is limited and this warrants further investigation. Upon further examination of the results of the regression analysis, it ms $a b-$ served that effects of this construct on fle successful integration of the companies at at positive $\left(R^{2}=0.255\right)$. Yet, multicollinean 1 y may be $\mathrm{r}-$ sponsible for the negative impacarehis constry on the model. This assumptionould sup or $41 \mathrm{e}$ value of the structural tes (0) 485). Additignally, the importance for the ccessful in $e_{8}$ ration of enterprise structures d ring MerA demonstrate the significance of the constrent that characterize the entrepreneuria oriecreativity, and innovation.

\section{Conclusion}

In general, it should be noted that the hypotheses about the impact of strategic competencies for successful integration of enterprise structures are confirmed. Regression analysis of the impact of social, firm-wide, and operational competencies shows the relationship between the level of development that is necessary for the successful integration of enterprise structures (see Table 3 ). The adjusted coefficient of determination $R^{2}$ for these competencies were $17.1 \%, 19.3 \%$, and $28.9 \%$, respectively. Regression analysis indicates that the competencies having the greatest impact on the successful integration are the strategic and operational competencies of business structures.

The last point of the study of the general model is that the positive impact of dynamic business environment on the success of the integration of enterprise strucures, (see Table 3) has not been identified. Be a-1 nox (-0.023), as well as structural factors, point to a nerat ve relationship between marke forces and ntegration success. This relations hip conforns yith the result of the discrim nant analysis and the regression analysis of the market onditions. Thus, the success of interation is more likely to be in the static and easily redictable narkets.

In ane analysis of the mutual influence of organization ay competencies, this research found that the lowest correlation interaction is located in the areas of the firm-wide and social competencies. This result can be due to the difference between the employee's goals and the manager's goals. The employee may have different goals that are in opposition to the managers. Although the managers are more concerned with the competencies in their pursuit of the optimization of production processes and implementation of IT-technologies, the employees may be more concerned with the social competencies. This may create a conflicting focus of the processes; the firm-wide processes focus on the functionality of the organization while the development of the social competencies is focused on internal factors such as team building, socialization of staff, and the formation of a comfortable corporate structure, and, therefore, conflict with firm-wide competencies that are focused on the efficiency of business processes.

All in all, it could be argued that the successful integration of enterprise structures is substantially determined by the formation and development of competencies (see Table 3). Moreover, the company can successfully respond to the dynamic changes in market conditions. 


\section{References}

1. Krishnakuman, D. \& Sethi, M. (2012). Methodologies used to determine mergers and acquisitions' performance. Academy of Accounting and Financial Studies Journal 16(3), 75-91.

2. Haspeslagh, P. C. \& Jemison6 D. B. (1991). Managing Acquisitions: Creating Value Through Corporate Renewal. New York: Free Press, 416.

3. Stacey, R. L. (2012, July/August). The key to M\&A success: Validate the value of the acquisition to the buyer. The Value Examiner, 13-15.

4. Kummer, C., \& Steger, U. (2008). Why merger and acquisitions (M\&A) waves reoccur: The vicious circle from pressure to failure. Strategic Management Review, 2(1), 44-63.

5. Newmeyer, C. E., Swaminathan, V. \& Hulland, J. (2016). When products and brands trade hands: A framework for acquisition success. Journal of Marketing Theory and Practice, 24(2), 129-146. doi: 10.1080/10696679.2016.1120539.

6. Marks, M. L., \& Mirvis, P. H. (2011a). A framework for the human resources role in managing culture in mergers and acquisitions. Human Resource Management, 50(6), 859-877. doi: 10.1002/hrm.20445.

7. Marks, M. L. \& Mirvis, P. H. (2011b). Merge Ahead: A Research Agenda to Increase Merger and Acquisition Success. Journal of Business \& Psychology, 26(2), 161-168.

8. Terranova (2007). Assessing culture during an acquisition. Organizational Development Journal, 25(1), 43-48.

9. Shemetov, E. A. (2012). Metody otsenki effektivnosti integratsii organizatsiy. In Russian [Methods for evaluating the effectiveness of the integration of the organizations]. Sovremennyye problem nauki i bratovaniya [Modern Problems of Science and Education], 1. Retrieved from: http://www.science-education.ru/101-53. (Woe of access: 10.09.2013).

10. Cartwright, S., \& Shoenberg, R. (2006). Thirty years of mergers and acqui - mons rosearch-Recent advances and future opportunities. British Journal of Management 17, 1-5. doi: 10.1111/j.1467-855 2006.00475.x

11. Crevens, D. (2012). Strategic Marketing, 10th edition. McGraw Hill/ru n. New Yo K, 4.

12. Tanure, B., Cancado, V. L., Duarte, R. G., \& de Muylder, C. F. (2009). The rol Or na hal culture in mergers and acquisitions. Latin American Business Review, 10, 135-159. doi: 101080/09785209031264.

13. Datta, D. K. (1991). Organizational fit and acquisition performnce: Effects of post-acquisition integration. Strategic Management Journal, 12(4), 281-297. doi: 10.1002/smj.4250/2p404/pdf.

14. Haspeslagh, P. C., \& Farquhar, A. B. (1994). The acquis ion in tegration rocess: A contingent framework. In: von Krogh, G., Sinatra, A., and Singh, H. (Eds). The Managen Sen of Corporate Aduisitions: International Perspectives. London: The Macmillan Press Ltd., 387.

15. Rudenko, M. N. (2015). Integration proceses in the enterpr se "Ekaterinburg. Publisher FGBUN Institute of Economics of the Urals Branch of the Russian Acat iny of Sciendes, 17 .

16. Krug, J. A., Wright, P. \& Kroll, M. J (244). Top management turnovers following mergers and acquisitions: Solid research to date but still much to berienned. Acad any of Management Perspectives, 28(2), 143-163. doi: 10.5465/ amp.2011.0091.

17. Blinda, L. E. (2007). Brand angement akil Offidentity-based brand management. German Universitatsverlag: Wiesbaden, 13-17. doi: 10.1007-078-3 8350-9518-

18. Cronbach, L. J. (1951). Ceffl ient alpha a d the internal structure of tests. Psychometricka, 16, 297-334.

19. DeVellis, R. F. (2012) Sule Developm le t: Theory and Applications. California: SAGE Publications, 205.

20. Santos, J. R. A. ( 999). Cronbach al ha:A tool for assessing the reliability of scales. Journal of Extension, 37(2), 1-5. http://www.joe.org/joe/1

21. Williams, B., Brown, T. \& a si ar, A. (2012). Exploratory factor analysis: A five-step guide for novices. Australasian Journal of Paramedicine, 8(3),

22. Durbin, J. \& Watson, G. S. (950). Testing for serial correlation in least squares regression I, Biometrika, 37, 409-428.

23. Durbin, J. \& Watson, G. S. (1951). Testing for serial correlation in least squares regression II. Biometrika, 38, 159178.

24. Durbin, J. \& Watson, G. S. (1971). Testing for Serial correlation in least squaresregression III. Biometrika, 58, 1-19.

\section{Authors}

Marina Nikolayevna Rudenko - Doctor of Economics, Associate Professor, Head of the Department of Entrepreneurship and Economic Security, Perm State National Research University (15, Bukireva St., Perm, 614990, Russian Federation; e-mail:m.ru.ko@mail.ru).

Rebecca Hochradel - Doctor of Phylosophy, Professor, Chair and Professor of Management, Delta State University (1003 W. Sunflower Road, Cleveland, 38733, United States of America; e-mail: rhochradel@deltastate.edu). 